\title{
Enhancing the Student Experience: Simulation-based Learning in the MBA Classroom
}

\author{
Diane Fittipaldi*, Mark Grenfell \\ St. Catherine University, USA.
}

How to cite this paper: Diane Fittipaldi, Mark Grenfell. (2020). Enhancing the Student Experience: Simulation-based Learning in the MBA Classroom. The Educational Review, USA, 4(7), 150-156. DOI: $10.26855 /$ er.2020.07.002

Received: July 16, 2020

Accepted: August 8, 2020

Published: August 14, 2020

Corresponding author: Diane Fittipald, St. Catherine University, USA.

Email: dfittipaldi@stkate.edu

\begin{abstract}
Business schools use computer-based simulations to teach students strategic decision-making skills in the context of real-world applications. Simulations fit well into the student-centered classroom where students take responsibility for their own learning and the professor offers guidance throughout. While much research focuses on students' perceptions of simulations as well as the measurable student learning outcomes that result from their use, little research exists on the evolution of students' mindsets as they move through the various rounds of a long-form simulation. This study documents the phases and shifts in students' self-efficacy and confidence as they work to successfully complete a complex, multi-round computer simulation in the context of a graduate business course. The results show a gradual but distinct pattern of improvement in the students' beliefs in their decision-making abilities, a dissipation of anxiety, the displacement of extrinsic motivations by intrinsic ones, and an increase in students' overall confidence.
\end{abstract}

\section{Keywords}

Attitudes, Business, Computer Simulations, Higher Education, Decision Making, Learner-Centered, Strategy

\section{Introduction}

Business schools face continuous pressure from employers to teach the skills needed to succeed on the job and yet many MBA programs fall short (Bennis \& O’Toole, 2005). A survey by Hart Research and Associates (2015), conducted on behalf of the Association of American Colleges and Universities, indicates 81\% of employers rate critical thinking and analytical reasoning skills as very important learning outcomes, which they expect students to obtain before they graduate. Similarly, $80 \%$ of employers rate the ability to apply knowledge to real world settings as very important (Hart Research and Associates, 2015). To assist in reaching these goals, many business schools use computerized simulations as part of the curricula. In fact, in 2016, a majority of business schools (56.8\%) reported using simulations, an increase of nearly 19\% compared to 2004 (Wellington, Hutchinson, \& Farial, 2017).

This wide usage stems, at least in part, from professors' understanding that simulations teach the skills employers seek. Simulations improve students' strategic competencies and decision-making ability and do so in an applied setting that mimics real life (Torres, Pedro, \& Augusto, 2017). In addition, students enjoy this method of learning. Specifically, they appreciate simulations for their value in building problem-solving skills and in honing their management decision-making abilities (Pratt \& Hahn, 2016). For Millennial students, the autonomy and interactivity of simulations fits these students' preferred style of learning (Proserpio \& Giola, 2007).

As a foundational element of a learner-centered curriculum, professors and students share power (Cullen, Harris, \& Hill, 2012). To give students a voice in what happens in the classroom, professors solicit feedback from students and 
use their input to make curricular changes. As a relatively new program, the MBA program in this study was launched with a curricular design, which included two classes taken in sequence as the last two courses in the program. These classes require students to synthesize the knowledge gained across their coursework and apply this knowledge, but in very different ways. In the first course, a business strategy class, students work in teams to launch and run a company in the context of a competitive online simulation exercise, which lasts seven weeks. In the second course, student teams work with an actual client through a capstone experience designed as a consulting project. The focus of this study is the business strategy course, which includes the simulation. Structured as an observational case study, the results presented here uncover an as yet undocumented attitudinal shift on the part of the students, which takes place at the mid-point of the seven-week simulation exercise. This shift adds to the growing body of research on this topic and helps professors better guide students through a simulation exercise to maximize self-efficacy, motivation and performance.

\section{Literature Review}

\subsection{Overview and history}

Langton, Addinall, Ellington, and Percival (1981) define simulations as having two constituent parts. First, simulations must represent a real-world situation and second simulations involve ongoing processes or operations. The authors draw distinctions between simulations and games but allow for a combined protocol which they call a "simulation game" defined as "an exercise that possesses the essential characteristics of games (competition and rules) and simulations (ongoing representation of real life)" (Langton, et. al., p. 16). In business education, the use of computerized simulations often includes the element of competition, whereby students compete against other groups of students, play against the computer or compete against themselves to achieve a personal best. Some simulations focus on singular objectives, often discipline specific with short run times. Others require students to integrate knowledge across domains, usually with multi-round formats taught over multiple class periods or all semester long (Rogmans, 2019).

A wide variety of professions, industries and organizations have used simulations as a training device for a long time. Flight simulators trace back to the 1930s with the Ocer Rocker and Ruggles Orientator, devices used to test and train pilots for both military maneuvers and commercial flight (Noe, 1989). In academia, medical students frequently encounter high fidelity simulations as part of their training. These simulations accurately reproduce clinical conditions and complex patient scenarios, allowing students to practice high-stakes procedures in a risk-free environment (Kothari, Khushali, \& Barach, 2017). Computerized simulations date back to 1947 with the development of a military program, which used a missile simulator as a training tool (Routledge, 2016). The use of simulation games for training management personnel started in the 1950s, soon thereafter spreading to business schools worldwide (Wells, 1990).

Business schools incorporate simulations into a variety of coursework. For example, Bal, Weidner, Leeds, and Raaka (2016) demonstrate the effective use of a simulation assignment in an undergraduate buyer behavior course. Simulations have also proven effective in operations management courses where students practice logistics modeling (Pasin \& Giroux, 2011). Finance classes use simulations to teach students how to manage investment portfolios (Dolvin \& Pyles, 2011). Importantly, this learning tool often finds its way into strategy courses because these courses typically require students to synthesize knowledge across a wide variety of learning experiences, understand the interdependencies between functional disciplines and integrate all of this in the service of making decisions (Kachra \& Schnietz, 2008).

\subsection{Advantages and disadvantages}

As a teaching technique, simulations offer several advantages. They are known to produce generative learning, whereby students connect ideas from one domain to another, forming durable patterns of knowledge (Zantow, Knowlton, \& Sharp, 2005). They achieve superior results for developing strategic decision-making skills, especially when compared to other methods of learning such as cases and lectures (Poisson-de Haro \& Turgut, 2012; Salas, Wildman, \& Piccolo, 2009). In keeping with the tenets of student-centered learning (Cullen, Harris, \& Hill, 2012), simulations help students move away from seeking right and wrong answers, improving their creative problem-solving abilities (Salas, et. al., 2009; Tompson \& Dass, 2000). Additionally, simulations put students in the center of their own learning while situating the professor as a guide to facilitate the process (Salas, et. al., 2009). At the same time, because simulations mimic workplace conditions where managers evaluate competing stakeholder demands, business schools rely on this form of learning to move students toward career readiness (Kachra \& Schnietz, 2008). Lastly, in addition to providing students with marketable skills, simulations improve students' confidence and self-efficacy (Tompson \& Dass, 2000). Importantly, self-efficacy is directly related to job performance and career advancement (Pan, Sun, \& Chow, 2011).

Student perceptions and reactions to simulations offer additional reasons for including this learning method into business school curricula. Students find simulations engaging (Salas, et al., 2009; Lu, Hallinger, \& Showanasai, 2014) 
and they enjoy them (Crocco, Offenholley, \& Hernandez, 2016). These attitudes exist independently from how well students perform on the simulation itself and from the grade they receive in the class (Anderson \& Lawton, 2009). In fact, business students rate courses with simulations more highly than other courses (Lu, et al., 2014; Thomson \& Dass, 2000). This halo effect extends to the ratings given to professors who teach simulation-based courses (Lu, et al., 2014). Students perceive simulations to be both interesting and novel and as a result, they expend more effort in these courses and report feeling they learned more than in courses which use other methods (Tompson \& Dass, 2000). Among the characteristics appreciated by students, receiving timely feedback and assessment information rank highly (Lu, et al. 2014).

While simulations offer many pedagogical advantages, a number of drawbacks also exist. For example, simulations require the professor to spend considerable time learning the way the exercise works in order to adequately prepare students (Kachra \& Schnietz, 2008). This includes taking time to fully comprehend rules of operation, training students on the software and knowing enough about the simulation to answer students' ongoing and detailed questions (Kachra \& Schnietz, 2008). From the student perspective, simulations may also present challenges. For example, Poisson-de Haro\& Turgut (2012) report some students become infatuated with the game-like algorithms inherent in the program's code and focus on trying to game the system rather than concentrating on making sound strategic decisions. In terms of outcomes and learning, while simulations are lauded on many levels, many emphasize the development of hard skills with less attention paid to social responsibility concerns or ethical considerations (Kachra \& Schnietz, 2008; Poisson-de Haro \& Turgut, 2012).

\subsection{Implementation strategies}

For professors opting to include simulations in their syllabi, research points to a number of recommendations for implementation. As noted by Schwartz (2013), simulations typically require a knowledge-to-action orientation, or bridging of theory and practice. To accomplish this goal, Warren and Crookall (2009) recommend a three-part instructional approach which calls for the teaching of content, followed by a simulation run, followed by a debrief of some kind. In this approach, the teaching of the content may cover theoretical concepts and other discipline specific lessons (Schwartz, 2013). Kriz (2010) recommends a similar approach but emphasizes the need to do pre-work prior to delving in. For example, once teams have been established, professors can use warm up exercises to form trust among team members and establish team culture, a key component in predicting simulation performance (Ritchie, Fornaciari, Drew, \& Marlin, 2013). Kriz (2010) goes on to suggest the need for a simulation briefing, delivered before work begins, to clearly outline the objectives or the assignment, the rules of the simulation and to review the role(s) of those involved, including the role of the professor.

Professors bear responsibility for more than just managing the students' progress through the simulation because the actions (or inactions) of the professor affect student performance (Wenzler \& Kriz, 2009). Broadly, the professor works with students to turn knowledge into action (Warren \& Crookall, 2009). On a more detailed level, the professor serves various functions, which shift as the simulation plays out. At the onset, the professor learns the simulation in detail and conducts an information session with students, preparing them for what is to come (Kris, 2010). Wagemann (as cited in Kris, 2010) considers this the role of the "shaper," or someone who sets the stage for the assignment. However, throughout the process, the professor takes an active stance, not only to answer questions and clear up confusion but also to observe students' decision-making process and witness their group dynamics in case interventions become necessary (Kris, 2010). In the classroom, the professor also guides students on matters of strategy, bringing up critical questions to challenge their thinking and improve their performance (Schwartz, 2013).

Reflection and debriefing stand as critical aspects of facilitating simulation assignments. These activities form the foundation for what Schwartz (2013) calls "Integration-action-knowledge" (p. 63) where the debrief helps students make the necessary connections to turn the results of their actions into knowledge. Similarly, Warren and Crookall (2009) claim "it is in the critical action of debriefing that these two strands [theory and practice] can be woven in a more balanced way, in preparation for the next round of the participation” (p. 21). To prepare for the debriefing, professors sometimes ask students to keep reflection notes or a "manager's diary" (Mawdesley, Long, Al-Jibouri, \& Scott, 2011, p. 46). This practice works well with the first phase of debriefing suggested by Kriz (2010), which asks students to describe their feelings about the experience of conducting a simulation run. Kriz (2010) goes on to suggest five additional phases of debriefing, moving from initial reactions to deep learning. These phases include: itemizing students' observations about the game itself; making connections between simulated reality and real life; detailing students' learning; developing hypotheses for future runs; and, drawing conclusions or implications from the experience. An alternative form of debriefing found to be popular with students involves giving presentations, which address their observations, learnings and implications (Mawdesley, et al., 2011). This method not only improves engagement but also of- 
fers students ideas for improving performance (Mawdesley, et al. 2011).

\subsection{Summary}

A growing body of research points to the effectiveness of simulations to develop students' strategic decision-making skills, helping them not only apply their knowledge but also helping them gain the confidence they need to succeed on the job (Poisson-de Haro \& Turgut, 2012; Salas, et al., 2009; Tompson \& Dass, 2000). Students enjoy this method of learning more than other methods and report greater levels of engagement and motivation (Salas, et al., 2009; Lu, et al., 2014). While satisfaction surveys provide feedback on student perceptions of this mode of teaching, what is missing from the research is first-hand observation of students' experiences with long-form simulation assignments from a professors' point of view. An examination of this kind will help faculty understand what to expect in the classroom in terms of students' developmental stages as they move through simulation assignments from start to finish.

\section{Methodology}

In an observational case study, data collected byway of a participant-observer forms the basis for analysis, often supplemented with a review of documents or interviews (Bogdan and Biklen, 2007). Studies like this focus on a particular activity in a specific setting. In this case, the activity and setting included a multi-round, capstone computer simulation used in an upper-level strategy course in an MBA program at a midwestern private university. All students in the study worked full time with a wide range of years of work experience, averaging eleven years overall. Ninety-five percent of the student body was female. All students had 36 MBA credits, approximately $85 \%$ of their degree requirements.

The study included observations across eight sections of the strategy course from 2015 through 2019. All eight sections included the same simulation assignment and were taught be the same professor. Students in all eight sections attended class one night per week for seven weeks. Prior to the first meeting, students completed two rehearsal rounds as individuals. This assisted them in assimilating the professor's guidance (received online) and allowed them to formulate questions for the initial class meeting. Students self-selected groups in week one with group size held to five or fewer students. Once teams were assembled, they received a full briefing by the professor. Teams then performed two practice rounds to familiarize themselves with the simulation, refine their team organization, and evaluate their team decision making approach. Over the next five weeks, teams completed eight simulation rounds. In the last week of the course, students developed formal presentations, which served to stimulate whole-class, large group discussions.

Professor observations took place from 2015 through 2019. These observations were collected by the one professor who taught all the courses in this study. Observation data were supplemented by student course evaluations over the same time period as well as MBA exit survey responses collected among program graduates from 2017 through 2019. The authors organized the data into codes. Three general categories of codes emerged (see Table 1): perspective codes, which defined students' shared understanding of the simulation; context codes, which placed the study in the larger body of research on simulations; and process codes, which identified the mindset phases experienced by students (Bogdan \& Biklen, 2007). The perspective codes were derived from observations, student comments and course evaluation data. The context codes and process codes stemmed mainly from direct observation.

Table 1. Simulation-based Learning Student Experience Coding Hierarchy

\begin{tabular}{|c|c|c|c|c|c|}
\hline \multicolumn{2}{|c|}{ Perspective Codes } & \multicolumn{2}{|c|}{ Context Codes } & \multicolumn{2}{|c|}{ Process Codes } \\
\hline $\begin{array}{l}\text { Exceeded my ex- } \\
\text { pectations }\end{array}$ & Most enjoyable class & $\begin{array}{c}\text { Knowledge from } \\
\text { action }\end{array}$ & $\begin{array}{c}\text { Final presentation as } \\
\text { debrief }\end{array}$ & $\begin{array}{c}\text { Analysis paraly- } \\
\text { sis }\end{array}$ & $\begin{array}{l}\text { Identifying roles and } \\
\text { responsibilities }\end{array}$ \\
\hline $\begin{array}{l}\text { Expected the most } \\
\text { out of me }\end{array}$ & Most valuable class & $\begin{array}{l}\text { Bridging theory } \\
\text { and practice }\end{array}$ & $\begin{array}{l}\text { Lecture on game } \\
\text { theory }\end{array}$ & $\begin{array}{l}\text { Anxiety gives } \\
\text { way to ease }\end{array}$ & $\begin{array}{l}\text { Students attending office } \\
\text { hours for help }\end{array}$ \\
\hline $\begin{array}{l}\text { Great use of group } \\
\text { work }\end{array}$ & Overwhelming & $\begin{array}{l}\text { Debrief develops } \\
\text { knowledge }\end{array}$ & Lecture on strategy & $\begin{array}{l}\text { Developing co- } \\
\text { hesion }\end{array}$ & $\begin{array}{l}\text { Taking time to under- } \\
\text { stand the rules }\end{array}$ \\
\hline Learned the most & Tough & Professor as coach & $\begin{array}{l}\text { Need to read all the } \\
\text { material }\end{array}$ & Feeling confident & $\begin{array}{l}\text { Transforming from doubt } \\
\text { to certainty }\end{array}$ \\
\hline Intense & Stretched me & $\begin{array}{l}\text { Professor as simu- } \\
\text { lation expert }\end{array}$ & $\begin{array}{l}\text { Pre-simulation } \\
\text { briefing }\end{array}$ & $\begin{array}{l}\text { Fretting over } \\
\text { grades }\end{array}$ & Wanting to compete \\
\hline $\begin{array}{l}\text { Most challenging } \\
\text { class }\end{array}$ & $\begin{array}{l}\text { Took on my responsibil- } \\
\text { ity for learning }\end{array}$ & & & & \\
\hline
\end{tabular}




\section{Results}

Data gathered under the perspective codes and context codes largely confirmed the existing body of research, while the process codes identified new insights into the attitudinal shifts experienced by students as the simulation unfolded over time. Results which validate existing research cover the following: high levels of student engagement and enjoyment for the course and the simulation (Crocco, et al., 2016; Lu, et al., 2014; Salas, et al., 2009), high ratings given to the course and the professor (Lu, et al., 2014; Thomson \& Dass, 2000), the effectiveness of the teaching protocol and process (Kriz, 2010; Warren \& Crookall, 2009), confirmation of the various and shifting roles of the professor (Kriz, 2010; Schwartz, 2013) and the value of student debriefing presentations (Mawdesley, et al., 2011).

The process codes uncovered attitudinal shifts experienced by students, not identified in previous research. Specifically, as the course unfolded and students gained experience with the simulation, their attitudes changed. These attitudinal shifts are depicted in the mindset map in Figure 1.

\begin{tabular}{|c|c|c|c|c|c|c|}
\hline Mixed Emotions & Angst/Doubt & & & & \multicolumn{2}{|c|}{ Certainty/Self-efficacy } \\
\hline $\begin{array}{l}\text { Practice } \\
\text { Week } 1\end{array}$ & $\begin{array}{c}\text { Simulation Week } \\
2\end{array}$ & Simulation Week 3 & $\begin{array}{l}\text { Simulation } \\
\text { Week } 4\end{array}$ & Simulation Week 5 & Simulation Week 6 & $\begin{array}{l}\text { Final Debrief } \\
\text { Week } 7\end{array}$ \\
\hline $\begin{array}{l}\text { This may be } \\
\text { interesting }\end{array}$ & $\begin{array}{l}\text { I am over- } \\
\text { whelmed }\end{array}$ & $\begin{array}{l}\text { There is an over- } \\
\text { whelming amount of } \\
\text { data }\end{array}$ & $\begin{array}{l}\text { The reports are } \\
\text { useful }\end{array}$ & $\begin{array}{l}\text { I feel good about } \\
\text { how my team is } \\
\text { performing }\end{array}$ & $\begin{array}{l}\text { Our team is perform- } \\
\text { ing well }\end{array}$ & $\begin{array}{l}\text { This was an ex- } \\
\text { cellent class }\end{array}$ \\
\hline $\begin{array}{c}\text { I'm a little uncer- } \\
\text { tain but excited to } \\
\text { try }\end{array}$ & $\begin{array}{c}\text { This seems com- } \\
\text { plicated }\end{array}$ & This is hard & $\begin{array}{l}\text { The debrief } \\
\text { helped }\end{array}$ & $\begin{array}{l}\text { My team's strategy } \\
\text { discussions are rich }\end{array}$ & $\begin{array}{l}\text { I feel confident about } \\
\text { what we are doing }\end{array}$ & $\begin{array}{l}\text { This class was a } \\
\text { challenge in a } \\
\text { good way }\end{array}$ \\
\hline $\begin{array}{l}\text { I don't understand } \\
\text { how this works }\end{array}$ & $\begin{array}{l}\text { This is going to } \\
\text { be hard }\end{array}$ & $\begin{array}{l}\text { I'm not sure I can do } \\
\text { this }\end{array}$ & $\begin{array}{l}\text { Professor office } \\
\text { hours helped }\end{array}$ & $\begin{array}{l}\text { I understand how to } \\
\text { use the reports }\end{array}$ & $\begin{array}{l}\text { I think we can master } \\
\text { this }\end{array}$ & $\begin{array}{l}\text { This class } \\
\text { stretched my } \\
\text { thinking }\end{array}$ \\
\hline $\begin{array}{l}\text { This seems } \\
\text { daunting }\end{array}$ & $\begin{array}{l}\text { I don't think I can } \\
\text { do this }\end{array}$ & $\begin{array}{l}\text { Will I get a good } \\
\text { grade? }\end{array}$ & $\begin{array}{l}\text { My team is } \\
\text { working well } \\
\text { together }\end{array}$ & $\begin{array}{l}\text { I feel good about } \\
\text { the strategy we } \\
\text { developed }\end{array}$ & $\begin{array}{l}\text { I feel like we accom- } \\
\text { plished something } \\
\text { great }\end{array}$ & I learned a lot \\
\hline \multirow[t]{2}{*}{$\begin{array}{l}\text { Will I like my } \\
\text { team? }\end{array}$} & $\begin{array}{l}\text { Will I get a good } \\
\text { grade? }\end{array}$ & The debrief helped & $\begin{array}{c}\text { I think we can } \\
\text { do this }\end{array}$ & $\begin{array}{l}\text { I want to do better } \\
\text { than the other teams }\end{array}$ & & \\
\hline & $\begin{array}{l}\text { This class might } \\
\text { hurt my GPA? }\end{array}$ & $\begin{array}{l}\text { Professor office } \\
\text { hours helped }\end{array}$ & $\begin{array}{l}\text { We might get a } \\
\text { good grade }\end{array}$ & & & \\
\hline
\end{tabular}

Figure 1. Student Mindset Map.

In week one of the course, students learned about the assignment and received a full briefing. Their homework assignment required them to complete two practice rounds of the simulation in their teams. At this stage, students showed mixed emotions ranging from excitement to curiosity to trepidation. After the practice rounds, the vast majority of students expressed anxiety. This anxiety took several forms. Many felt daunted by the perceived difficulty of the simulation. The amount of preparatory reading material seemed overwhelming and the feedback reports and analysis stemming from the practice rounds seemed too voluminous and complex to digest. Others revealed overt concern about the potential for an inferior grade on the assignment and by extension in the class. During this early period, students frequently attended office hours to express concerns and took time after class to receive individualized guidance. These sessions demonstrated students' desire to develop the correct inputs (decisions) into the simulation. In other words, students had a right/wrong orientation. Additionally, students often asked, "How do we win?" This orientation ultimately gave way to a realization that in a competitive marketplace, many businesses can function or "win". Never does one car company or soap company monopolize all the sales. Students eventually came to realize a competitive market benefits consumers and forces companies to optimize.

Shifts in these attitudes proved gradual but by the mid-point of the simulation, the change was noticeable. Anxiety and doubt softened, but did not disappear entirely. Students began to settle into their roles on their teams, teams developed cohesion and tasks seemed less daunting. In-class debriefs, large group discussions and team breakout meetings helped students turn their actions into knowledge. As they gained knowledge, they gained confidence. Attendance at office hours dropped and students relinquished their right/wrong inclinations in favor of understanding the nuanced nature of business decision making and marketplace competition.

On the last evening of the course, teams presented their findings to the class. These presentations outlined the teams' approaches, the simulation outcomes and lessons learned. It was during these presentations that the full depth and contrast of the students' attitudinal shift showed itself. By the end of the course, students emerged as fully confident and 
satisfied with their learning regardless of how well their teams did on the simulation. Importantly, they sourced their satisfaction intrinsically rather than extrinsically, meaning angst over grades dissipated. Lastly, students saw themselves as the center of their own learning, realizing the professor's role was to set the stage and facilitate the process (Salas, et al., 2009).

\section{Discussion}

Simulations offer a valuable learning tool. They help students hone their decision-making skills (Poisson-de Haro \& Turgut, 2012) and offer students a risk-free setting to move into career readiness (Kachra \& Schnietz, 2008). This study confirms much of the available research on the advantages and value of simulations. Similar to the work of Pratt and Hahn (2016), students in this study perceived they learned a great deal from the experience. They enjoyed the process and were motivated by their work (Salas, et al., 2009; Lu, et al., 2014). In terms of pedagogical design and process, this study also confirmed the importance of team cohesion (Ritchie, et al., 2013) and the efficacy of the protocol, which included briefing, teaching content, running the simulation and debriefing (Kriz, 2010; Schwartz, 2013; Warren \& Crookall, 2009). Lastly, this study agreed with Kriz (2010) on the various roles the professor plays throughout the process to assure a learner-centered experience.

This study adds to the existing research by uncovering the changes in mindset experienced by students over the course of the multi-run simulation. A map of these gradual changes revealed over the course of seven weeks demonstrates the power of a student-centered classroom. Students moved from doubt to certainty and from anxiety to confidence. They eschewed notions of right and wrong answers in favor of higher order thinking along the lines of Bloom's Taxonomy (Crocco, et al., 2016). This study offers faculty an understanding of the phases of development experienced by students in this regard and helps professors better understand what to expect and therefore how to facilitate the process of teaching a course containing a long-form simulation.

\section{Limitations and Future Research}

As with all case studies, the findings here are specific to the setting and the participants in this study. By definition, a case study describes a phenomenon (Bogdan \& Biklen, 2007), which while valuable, is limited in its ability to predict the future. The findings of this study offer a hypothesis for future testing, specifically whether the student mindset shifts seen here, which evolve over the lifecycle of a long-form simulation, can be replicated. Of particular interest may be whether the phenomenon exists for simulations used by different disciplines such as healthcare. Additionally, this study was limited to graduate students with a great deal of on-the-job experience. Future studies may look at attitudinal shifts experienced by students at different degree levels and/or with varying degrees of work experience. Importantly, the participants in this study were overwhelmingly female. Future research may look at whether the phenomenon observed here exists for courses with different gender compositions and investigate the differences in mindset by gender.

\section{References}

Anderson, P. H., \& Lawton, L. (2009). Business simulations and cognitive learning: developments, desires, and future directions. Simulation \& Gaming, 40(2), 193-216.

Bal, A. S., Weidner, K., Leeds, C., Raaka, B., Kietzmann, J., \& Pitt, L. (2016). Getting real about suicide prevention in the classroom and beyond: using a classroom simulation to create communications for at-risk individuals. Journal of Marketing Education, 38(2), 90-97.

Bennis, W. G., \& O’Toole, B. (2005). How business schools lost their way. Harvard Business Review, 83(5), 96-104.

Bogdan, R. C. \& Biklen, S. K. (2007). Qualitative research for education: An introduction to theories and methods. Pearson Education. Boston, Massachusetts.

Crocco, F., Offenholley, K., \& Hernandez, C. (2016). A proof-of-concept student of game-based learning in higher education. Simulation \& Gaming, 47(4), 403-422.

Cullen, R. M., Harris, M., \& Hill, R. R. (2012). The learner-centered curriculum: design and implementation.San Francisco, CA: Jossey-Bass.

Dolvin, S. D., \& Pyles, M. K. (2011). The influence of simulation performance on student interest. Journal of Economics and Economic Education Research, 12(3), 35-48.

Hart Research and Associates. (2015). Falling short. College learning and career success. Association of American Colleges and Universities.

Kachra, A., \& Schnietz, K. (2008). The capstone strategy course: what might real integration look like? Journal of Management 
Education, 32(4), 476-508.

Kothari, L. G., Shah, K., \& Barach, P. (2017). Simulation based medical education in graduate medical education training and assessment programs. Progress in Pediatric Cardiology, 44, 33-42.

Kriz, W. C. (2010). A systemic-constructivist approach to the facilitation and debriefing of simulations and games. Simulation \& Gaming, 41(5), 663-680.

Langton, N. H., Addinall, E., Ellington, H. I., \& Percival, F. (1980). The value of simulations and games in the teaching of science. European Journal of Education,15(3), 261-270.

Lu, J., Hallinger, P., \& Showanasai, P. (2012). Simulation-based learning in management education: a longitudinal quasi-experimental evaluation of instructional effectiveness. Journal of Management Development, 33(3), 218-244.

Mawdesley, M., Long, G., Al-Jibouri, S., \& Scott, D. (2011). The enhancement of simulation based: learning exercises through formalized reflection, focus groups and group presentation. Computers \& Education, 56(1), 44-52.

Noe, A. (1989). Medical principle and aeronautical practice: American aviation medicine to World War II. (Doctoral dissertation). Retrieved from ProQuest Dissertations \& Theses Global (Order No. 9019301).

Pan, W., Sun, L., \& Chow, I. (2011). The impact of supervisory mentoring on personal learning and career outcomes: the dual moderating effect of self-efficacy. Journal of Vocational Behavior, 78(2), 264-273.

Pasin, F., \& Giroux, H. (2011). The impact of a simulation game on operations management education. Computers \& Education, 57(1), 1240-1254.

Poisson-de Haro, S., \& Turgut, G. (2012). Expanded strategy simulations: developing better managers. Journal of Management Development, 31(3), 209-220.

Pratt, M. A., \& Hahn, S. (2016). Enhancing hospitality student learning through the use of a business simulation. Journal of Hospitality, Leisure, Sport \& Tourism Education, 19, 10-18.

Proserpio, L., \& Gioia, D. A. (2007). Teaching the virtual generation. Academy of Management Learning \& Education, 6(1), 69-80.

Ritchie, W. J., Fornaciari, C. J., Drew, S. A. W., \& Marlin, D. (2013). Team culture and business strategy simulation performance. Journal of Management Education, 37(5), 601-622.

Rogman, T. (2019). When - and When Not - to choose a business simulation for your course:ahow-to guide for selecting simulations [Blog post]. Retrieved from https://hbsp.harvard.edu/when-and-when-not-to-choose-a-business-simulation-for-your-course/.

Routledge, H. (2016). Why games are good for business: how to leverage the power of serious games, gamification and simulations. London: Palgrave Macmillan.

Salas, E., Wildman, J. L., \& Piccolo, R. F. (2009). Using simulation-based training to enhance management education. Academy of Management Learning \& Education, 8(4), 559-573.

Schwarz, J. O. (2013). Business wargaming for reaching strategy Making. Future, 51, 59-66.

Thorngate, W., \& Crookall, D. (2009). Acting, knowing, learning, simulating, gaming. Simulation \& Gaming, 40(1), 8-26.

Tompson, G. H., \& Dass, P. (2000). Improving students' self-efficacy in strategic management: the relative impact of cases and simulations. Simulation \& Gaming, 31(1), 22-41.

Torres, P., \& Augusto, M. (2017). The impact of experiential learning on managers' strategic competencies and decision style. Journal of Innovation \& Knowledge, 2(1), 10-14.

Wellington, W. J., Hutchinson, D. B., \& Faria, A. J. (2017). Measuring the impact of a marketing simulation game: experience on perceived indecisiveness. Simulation \& Gaming, 48(1), 56-80.

Wells, R. (1990). Management games and simulations in management development: an introduction. The Journal of Management Development, 9(2), 4-6.

Wenzler, I., \& Kriz, C. W. (2009). The ten commandments for translating simulation results into real-life performance. Simulation \& Gaming, 40(1), 98-109.

Zantow, K., Knowlton, D. S., \& Sharp, D. C. (2005). More than fun and games: reconsidering the virtues of strategic management simulations. Academy of Management Learning \& Education, 4(4), 451-458. 